\title{
Transplantation of autologous peripheral blood stem cells improved diabetic peripheral neuropathy
}

Hong Bo Sun ${ }^{1}$, Sheng Mei Xia ${ }^{1}$, Yun $\mathrm{Li}^{1}$, Yan Zhao ${ }^{1}$, Wei Wei $\mathrm{Li}^{1}$, Hong $\mathrm{Li}^{1}$, Jing Wang ${ }^{1}$, Zhou Wang ${ }^{1}$, Xin Min Ding $^{1}$, Mei Wang ${ }^{2}$, Ming Zhe $\operatorname{Han}^{2}$

${ }^{1}$ Daqing Oil Field General Hospital, Daqing 163001; ${ }^{2}$ China Institute of Hematology \& Blood Diseases Hospital, Chinese Academy of Medical Scienes \& Peking Union Medical College, Tianjin 300020, China

Objective Investigate to the effect of transplantation of autologous peripheral blood stem cells on diabetic peripheral neuropathy of the patients with diabetic lower limb arteriosclerosis obliterans. Methods 20 patients, rhGCSF $600 \mu \mathrm{g} / \mathrm{d}$ for 5 days. On the fifth day, PBSC were collected. Sooner the PBSC were intramuscularly injected into the two limbs of patients. To do nerves and muscle electrophysiology examination of anticnemion and fibula nerves before and three months after autologous peripheral blood stem cells. Result Nerves and muscle electrophysiology examination of 38 lower limbs of 20 patients showed that latent period of anticnemion nervimotor was shortened, $4.91 \pm 1.42 \mathrm{mS}$ prior treatment, $4.56 \pm 1.47 \mathrm{mS}$, post-treatment, $p<0.05$. Anticnemion sensory nerves conduction velocity and wave amplitude significantly increased, $10.23 \pm 16.51 \mathrm{~m} / \mathrm{s}$ and $0.18 \pm 0.34 \mathrm{mV}$ prior treatment, $31.33 \pm 13.50 \mathrm{~m} / \mathrm{s}$ and $0.78 \pm 0.93 \mathrm{mV}$ post-treatment,both of them $p<0.05$, Latent period of fibula nervimotor was shortened too, $4.18 \pm 2.92 \mathrm{mS}$ prior treatment, $3.81 \pm 2.93 \mathrm{mS}$ post-treatment, $p<0.05$. Fibula nervimotor and sensory nerves conduction velocity significantly increased, $37.45 \pm 15.59 \mathrm{~m} / \mathrm{s}$ prior treatment, $40.69 \pm 15.96 \mathrm{~m} / \mathrm{s}$ post-treatment, $p<0.05$ and $30.89 \pm 20.31 \mathrm{~m} / \mathrm{s}$ prior treatment, $43.23 \pm 17.36 \mathrm{~m} / \mathrm{s}$ post-treatment, $p<0.05$, Conclusion Transplantation of autologous peripheral blood stem cells significantly improved the damage of diabetic peripheral neuropathy.

Keywords: lower limb peripheral neuropathy, improved, diabete, mobilization, transplantation

Cell Research (2008) 18:s84. doi: 10.1038/cr.2008.174; published online 4 August 2008 